\title{
On Developing an Integrated Family Mobile Application
}

\author{
Subhieh El-Salhi ${ }^{1}$, Fairouz Farouq ${ }^{2}$, Randa Obeidallah ${ }^{3}$, Mo'taz Al-Hami ${ }^{4}$ \\ Department of Computer Information System \\ Hashemite University, Zarqa, Jordan
}

\begin{abstract}
Now-a-days mobile applications have been seen as the most effective, popular and powerful technologies and this is due to the widespread of mobile devices. Moreover, the raising power of mobile devices has a great impact on people of all ages; and more specifically on social relationships including interaction between parents and kids. Therefore, this paper presents a highly integrated Family Mobile Application (FMA) that provides a wide range of services to control, manage, organize and support the different daily tasks of family members effectively. The essential tasks of the FMA are mainly described in terms of facilitating the daily life routine and responsibilities, enhancing the communication between the family members (in different aspects) and supporting the Augmented Reality (AR) which is directed to the children of the family to support educational goals in particular. Moreover, a website has been established to enrich the functionality of the proposed FMA application. The FMA has been analysed, designed, implemented and evaluated on real-world users of the system. The evaluation was con-ducted in terms of the usability testing that considers satisfaction, simplicity and ease of use. More details of the real evaluation are illustrated and presented.
\end{abstract}

Keywords-Mobile technology; social apps; family mobile application; Augmented Reality (AR)

\section{INTRODUCTION}

Generally speaking, parenting can be considered as the most difficult full-time job in the world as the parents need to stay connected with their children all the time to guide, support and take care of them. The difficulties of parenting come from two major factors: (i) to fulfill the parenting responsibilities in providing an adequate supervision constantly and (ii) to overcome the implication of the long hours of work-load. Furthermore, these difficulties become more complicated if both parents are working due to economic, social and cultural reasons. Therefore, the most significant aspect of effective parenting skill requires reaching an ideal work-family balance.

Moreover, Sanders et al. highlights the most important competent parenting aspects [1]. Some of these aspects are summarized as follows (but not limited to): (i) providing positive learning environment, (ii) encouraging good behaviour in kids (assertive discipline), (iii) providing health nutrition, and finally (iv) encouraging cooperative behaviour and caring while handling household chores and family responsibilities. Therefore, there is an essential demand to employ the technology to fulfill the responsibilities of parents effectively.

The mobile apps development process has been increasingly influenced by nowadays-technological revolution and consequently it have been widely employed to facilitate the usage of various services provided by different fields such as health in the work presented in [2], education [3] and marketing [4]. However, most of the intensive work of the existing mobile applications is focused on developing and supporting a single task (service) that serve people in their social life effectively such as the secured mobile chat service application presented in [5].

Regarding mobile apps of social activities, a very limited work has been targeted to serve a group of people that are interested in some common shared tasks. To the best of our knowledge, there is no application directed to a single family. From this prospective, a Family Mobile Application (FMA) is proposed to support family members' lives in easier, simpler and more efficient way. The primary motivation for the work presented was a desire to provide a solution for the growing complexity of managing the daily routines of families and for enhancing the parental role. However, the FMA app is proposed not only to overcome the management challenges of the daily routines but also to provide a wide range of services that would strengthen the relationship between the family members.

Additionally, the family authorization is the key feature of the FMA application since it attempts to simulate the ParentChild relationships while providing the different services. Therefore, the FMA application can be seen as an integrated application aims to overcome the families social challenges (to some extend) in smooth, effective e and simple technological style.

The FMA app overcomes the major challenges of parenting by providing the following services:

1) Minimize the impact of the long working hours of parents and rigorous working conditions by staying connected with their children using both the chat services and GPS tracker to determine the location of their children accurately.

2) Contribute the entire family members in family decision-making process significantly (i.e. deciding the meal of the day).

3) Increase the collaboration among family members to achieve household duties.

4) Support parents' supervision and control over the assigned household tasks.

5) Increase the level of communication and sharing between the family members by reminding and notifying them with important events.

6) Support real learning environments through presenting some stories using Augmented Reality (AR) technology. 
The rest of the paper is organized as follows: Section II presents relevant literature reviews with a brief overview of some related studies. Section III introduces the functional requirement analysis for the proposed FMA app. More details on the interface design and development are demonstrated in Section IV. The evaluation of the application in terms of the usability is presented in Section V. Finally, some conclusions are presented in Section VI.

\section{Literature REVIEW}

With the rapid growth of internet technology, individuals are eager to obtain the recent new top mobile phones and hand held devices in order to use the latest mobile applications easily. The dynamic revolution of technology redefines the communication process between society members and facilitates the communication between the individuals and their friends and relatives. Recent studies offered by Sanders and Leung indicate the essential role of internet technology on keeping people in touch and enabling them to communicate easily, simply and efficiently more than before [1], [6]. Social researchers have been studying the impact of Information and Communication Technologies (ICT) for individuals, families, and work life in modern societies. Romero-Ruiz et al. in [7] explored and identified perceptions that influence the use of ICT on family life. In modern families, adults and children are using the internet in daily basis. According to Children and Parents: Media Use and Attitudes Report in 2017; 83\% of children aged from 12 to 15 have their own smart phones and $55 \%$ have their own tablets. Internet, software programs and mobile applications are used for school works, and more for entertainment purposes [6], [7], [8]. Few researchers noticed that family ties are becoming extremely difficult to maintain due to revolution of technology. Tensions between parents and children are increased due to the use of technology [9]. Another common perception showed that ICT do not favour family communication and this perspective found in [10]. However, the effect of ICT on modern family relationships was studied by Kerawalla et al. [8] and Kraut et al. [11] and concluded that family members spend less time in communicating and interacting face to face which may lead to damage family relationships. Romero-Ruiz et al. showed that virtual communication exposes families to feel lacking of affection [7]. On the other hand, Family members benefit of ICT to manage time, money and home activities. ICT helped parents to spend more time with family through taking care of business remotely [12]. Franzen found that internet and e-mail has a positive effect on conserving family social ties [13]. Richer communication methods that include face-toface communication, phone and video calls showed a positive relationship satisfaction as mentioned by Goodman-Deane et al. [14]. Yet, text messaging and instant messaging were negatively associated. Family life activities are modified and moderated by ICT [15]. The positive or negative impact of ICT is determined by the way ICT is managed by parents. In order to maintain a healthy family relationship, parents need to manage the use of technology inside homes. Technology should be supervised by parents to handle the effect of technology on children's educational, emotional and social development. Parents need to determine what is the appropriate technology to use and the amount of time spent using it at home [16]. Many attempts were made to develop mobile applications to help parents to supervise children's activities, chores and locate child's location. It is familiar that family activities are usually planned and coordinated through a calendar known as family calendar. Digital family calendar is now used as a replacement of paper calendar. Neustaedter et al. proposed a digital family calendar called inkable family calendar (LINC) and examined its positive effect on four families in their study [17]. Another example of family organizer mobile application is Cozi [18]. Cozi has a calendar that can be used by the entire family, "to do list" where you can create a shared to do list, and chore list for the kids, keep family journal and recipes. In modern days, parents need to locate the location of children at all times. An android application was developed by Khan et al. [19] that can be used in emergency cases to send the current address location of a mobile device through an SMS message to a user, in our case the user is the parent. Maghade et al. developed an android application based on GPS and SMS services in Android mobile [20]. SMS service is used when smart phones do not have internet connectivity. Sweidan et al. proposed a system called "kids' tracker" that includes a wearable gadget for the child and an android application installed on parents' smart phone, this system does not need to give a mobile phone to the child [21].

\section{The Proposed FMA ApP FUnCTIONAL REQUIREMENT}

This section presents a full description for the proposed FMA app through presenting the structure of the FMA app and the functionality of the proposed FMA app in Section III-A and Section III-B, respectively.

\section{A. The FMA App Structure Overview}

The structure of the proposed FMA is presented in this section using the class diagram. The class diagram presented in Fig. 1 shows the structure of the different types of services that the family members can use and get beneficial from it. Additionally, it shows that the FMA app consists mainly of two types of users: parents and children. Parents start up the app and create the family account. After that the rest of family members including the children start to register and join the family account simply and easily.

Assuming that the FMA app is going to be downloaded on parent's mobile from the website. The complete picture of registration process for different user types and family account creation is fully described in the following steps:

- $\quad$ With respect to parent (considered as admin):

1) For the first time, one of the parents has to register and create the family account by either (i) filling a sign up form or (ii) using his Facebook account.

2) Determine the type of user (in this case it would be a parent).

3) Create the family account so the members can then be added individually.

- With respect to children:

1) Children apply the above step 1 and determine the type of user as children in step 2 .

2) Then search for the name of their family account. If it is found then they can ask to join 


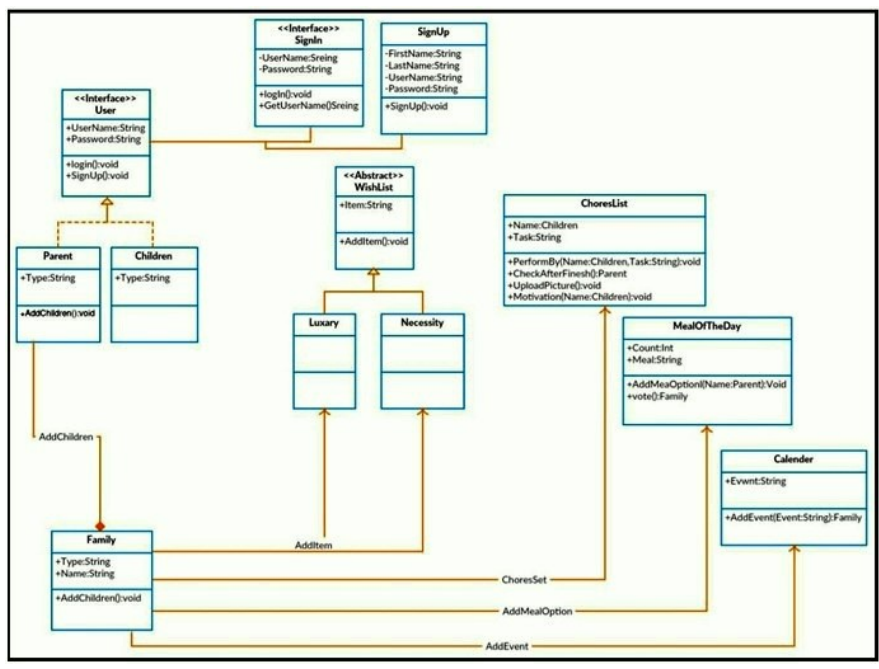

Fig. 1. The class diagram of the FMA app.

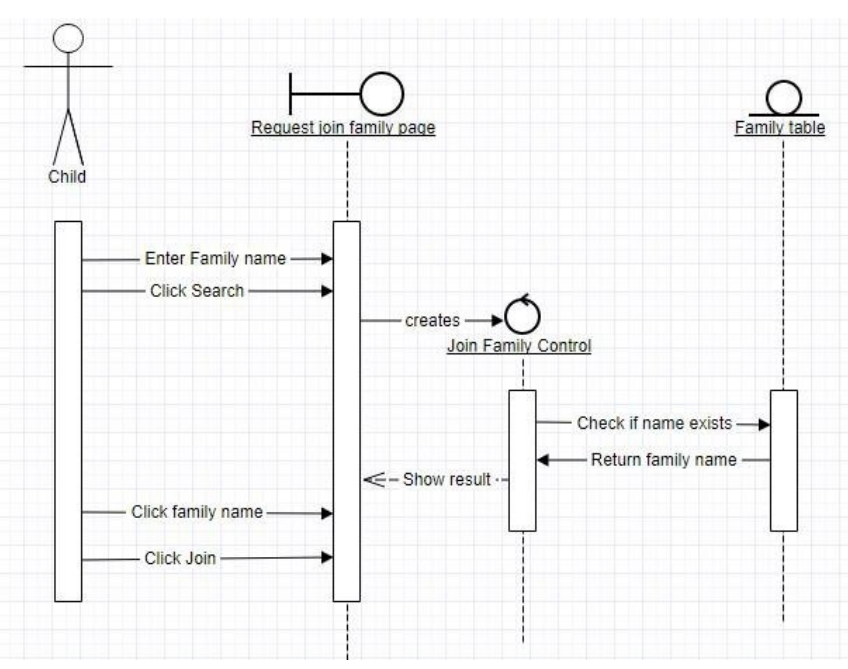

Fig. 2. The Sequence diagram of creating accounts for children.

the family to be a member in (as shown in Fig. 2). Otherwise, they can do nothing but waiting their parents to create the family account.

It is worth to mention that, the concept of parental authority of the parents towards their children appears clearly in the FMA app as the role of creating family account and adding family members are identified as one of the parents' responsibilities and this is a typical example of a real life imitating.

\section{B. System functionality}

As previously mentioned, the FMA app provides a wide set of services and functions to the family members once the family account is created. We have two main actors: parents and children. The set of functionality and services are going to be discussed and fully described according to user type.

- $\quad$ For the parents, the main functions are: (i) accepting and rejecting the members request to join the family, (ii) assigning different chores such as vacuuming,

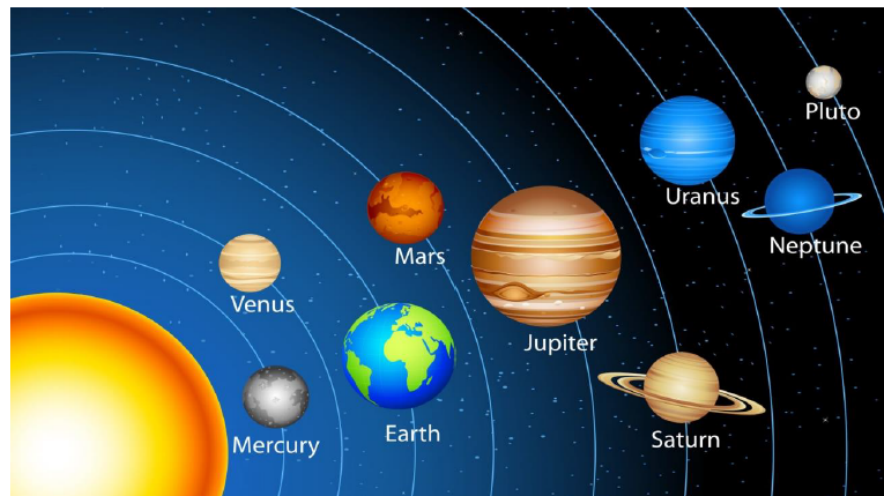

Fig. 3. The Solar system.

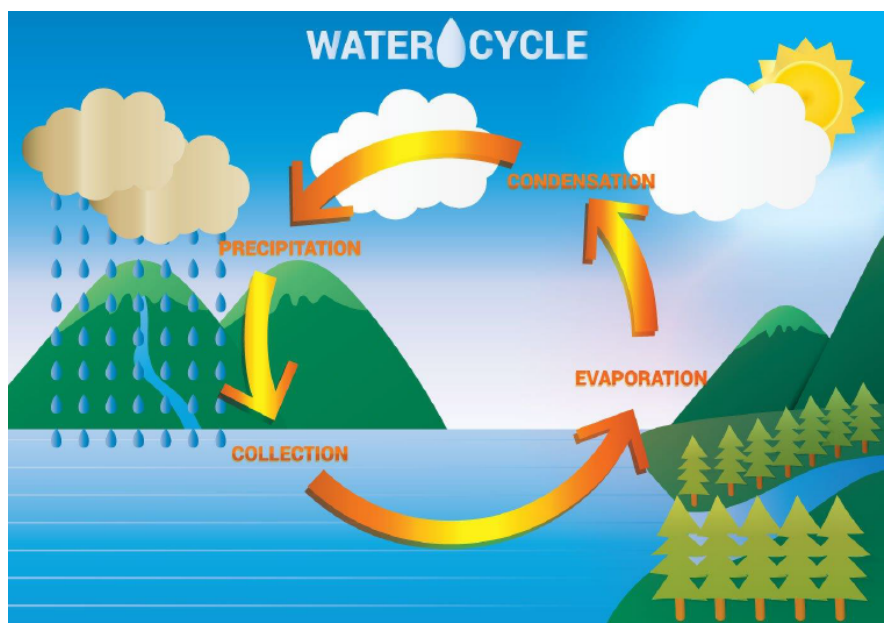

Fig. 4. The Water cycle.

sweeping and dusting to children, (iii) monitoring and check the progress of the assigned tasks, (iv) suggesting a meal to the "meal of the day".

- $\quad$ For the children, the main functions are: (i) reporting the completed as-signed task (chores) and (ii) voting to the preferred meal from the suggested list meals ("meal of the day") where the meal with the majority votes wins.

However, both parents and children have some common set of tasks such as: (i) adding items to the "wishing list", (ii) monitoring and checking the place of family members, (iii) chatting with each other, (iv) adding and viewing significant activities of the dynamic calendar such as parent meetings at schools, exam schedules and doctor appointments, and lastly (v) using AR technology to explore some stories. Two scientific stories have been used with respect to AR stories: the solar system and the Water cycle story shown in Fig. 3 and Fig. 4, respectively.

Furthermore, as good deeds deserve pay off at the end, the concept of rewarding the children appears clearly in the "wishing list" service. The "wishing list" has two different types: (i) luxury list which contains the desired items children wishing to own on different occasions such as branded clothing and accessories (i.e. watches and jewelry) and (ii) ordinary 


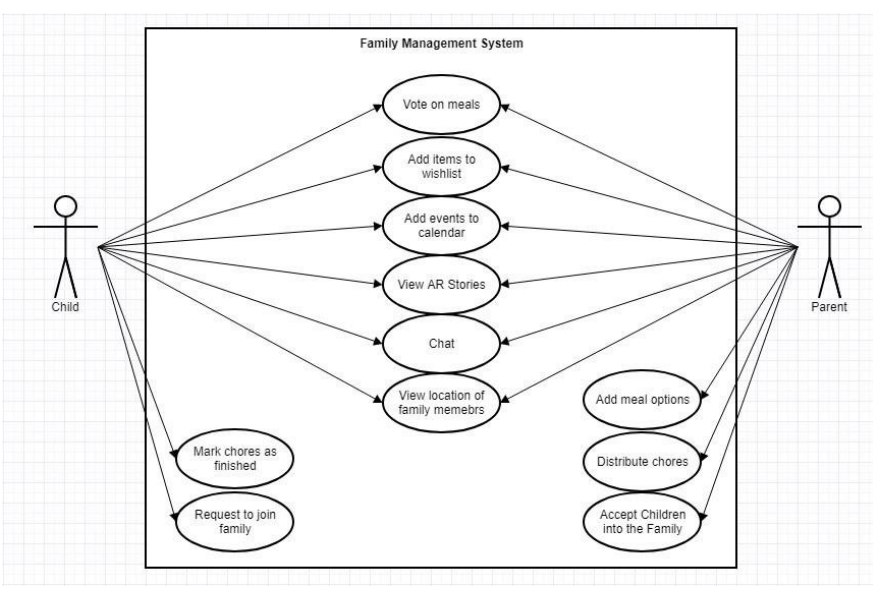

Fig. 5. The Use-case diagram of the provided services of FMA app.

shopping list which contains the basics and daily necessities (i.e. groceries items). It is worth to mention that the children earn points for each successfully completed task that was already as-signed to them by their parents. More accomplished tasks mean more points that are collected. Once the collected points reach certain number of points "level" (determined by the parents), the luxury list is activated and the children are awarded to list their desired valuable items they are willing to obtain. After that, the parents can easily select the items from the luxury list if they decided to reward their children for their high assistance and effective collaboration in household activities especially in special occasions (i.e. birthdays and exams). With reference to Fig. 5, the details of each functional requirement (FR) performed in the FMA app are listed below using Cockburn template [22], [23]:

FR1: Accepting children's request (i.e., registration)

Use case Title: Accepting children's request

Primary Actor: Parent

Stakeholder: Parent, Children

Precondition: Parents create family account successfully and children need to download the FMA app and enter valid data (family name)

Minimal Guarantee: Failed to join the family (reject the request)

Success Guarantee: Children join the family successfully.

Trigger: Download the FMA app from and ask to join the family

Main success scenario:

1. Children download the FMA app from the website successfully

2. Children Search the family name

3. Children send a request to join the family

4. Parent accept the request

Extensions:

1) If the FMA app is not downloaded successfully

a Children take action to explore the website and download the app again

2) Children cannot find the name of family

a Children quits the app. Children wait their parent to create family account

FR2: Distribute Chores including the following:
Use case Title: Distribute Chores

Primary Actor: Parent

Stakeholder: Parent, Children

Precondition: Parents and children need to register to the FMA App and join the family account successfully

Minimal Guarantee: Chores are not assigned

Success Guarantee: The application successfully assigns task to one family member.

Trigger: The parents need to check the list of daily chores to distribute among family members.

Main success scenario:

1. Parents check the chores

2. Parents assign the task for a single family member

3. Child checks the assigned task

4. Child finishes the assigned task and marks the task status as completed

5. Parent check the completed tasks and accept it

6. Child collects points for the successfully completed task

Extensions: N/A

FR3: Add meal to the "meal of the day" including the following:

Use case Title: Add meal

Primary Actor: Parent

Stakeholder: Parent, Children

Precondition: Parents and children need to register to the FMA App and join the family account successfully

Minimal Guarantee: N/A

Success Guarantee: The parent can easily update (add or delete) the meal list so the family members can explore the suggested meal list and vote for their favorite one and the meal of the day is successfully determined

Trigger: The parents need to check the meal list in order to update it

Main success scenario:

1. Parents check the meal list

2. Parents add/delete the meal list

3. Parents and children vote for the preferred meal

4. Parent check the completed tasks and accept it

Extensions: N/A

FR4: Add item to list including the following:

Use case Title: Add item to list

Primary Actor: Children

Stakeholder: Parent, Children

Precondition: Parents and children need to register to the FMA App and join the family account successfully. Child needs to collect the minimum number of point to activate the luxury list

Minimal Guarantee: Luxury list is not activated

Success Guarantee: The child can update (add or delete) the most desired items on the luxury list successfully

Trigger: The child needs to activate the luxury list through collecting the required number of points

Main success scenario:

1. The child collects the required points results from the accomplished tasks

2. The collected points activate the luxury list

3. The child can list the desired items on the luxury list

4. Parent can check the luxury list

Extensions: N/A 
FR5: Add important event to the calendar including the following:

Use case Title: Add important event to the calendar

Primary Actor: Parent, children

Stakeholder: Parent, Children

Precondition: Parents and children need to register to the FMA App and join the family account successfully.

Minimal Guarantee: N/A

Success Guarantee: The child can update (add or delete) the important events on the calendar

Trigger: The parent and children need to check the calendar Main success scenario:

1. The parent and children check the calendar

2. The parent or children select the day and time of the important event

3. The parent or children update (add/delete) the calendar

4. The parent or children upload a document or an image for the specified important event

5. All the family member can see and browse the updated events

Extensions: N/A

FR6: View the location of family members including the following:

Use case Title: View (check) the location of family members Primary Actor: Parent, Children

Stakeholder: Parent, Children

Precondition: Parents and children need to register to the FMA App and join the family account successfully.

Minimal Guarantee: The parents and children cannot determine the location of other family members

Success Guarantee: The child or parent can track and determine the location of other family members accurately

Trigger: The parent and child explore the location

Main success scenario:

1. The child and parents check the location of other family members

Extensions: N/A

\section{INTERFACE DESIGN AND DEVELOPMENT}

Two types of platforms have been developed to support the FMA application; a website and a mobile application. The website is designed to promote the services and the functionality of the mobile application, give a brief description of the App and of course to support the downloading process of the FMA app easily, freely and safely. Different tools have been used in the development process of the mobile application that are: (i) Android Studio IDE that linked via Google API file, Google Firebase and Vuforia [24], [25]. The Firebase is an integrated mobile application development platform that is provided by Google. It is considered as a real time database. Unlike relation database, there are no tables or records. However, Firebase uses JavaScript Object Notation (JSON) tree structure and the stored data is simply represented as a node with reference key. Firebase covers a wide range of services such as authentication, databases, configuration, file storage and messaging. In addition to the aforementioned properties, Firebase has been used due to its

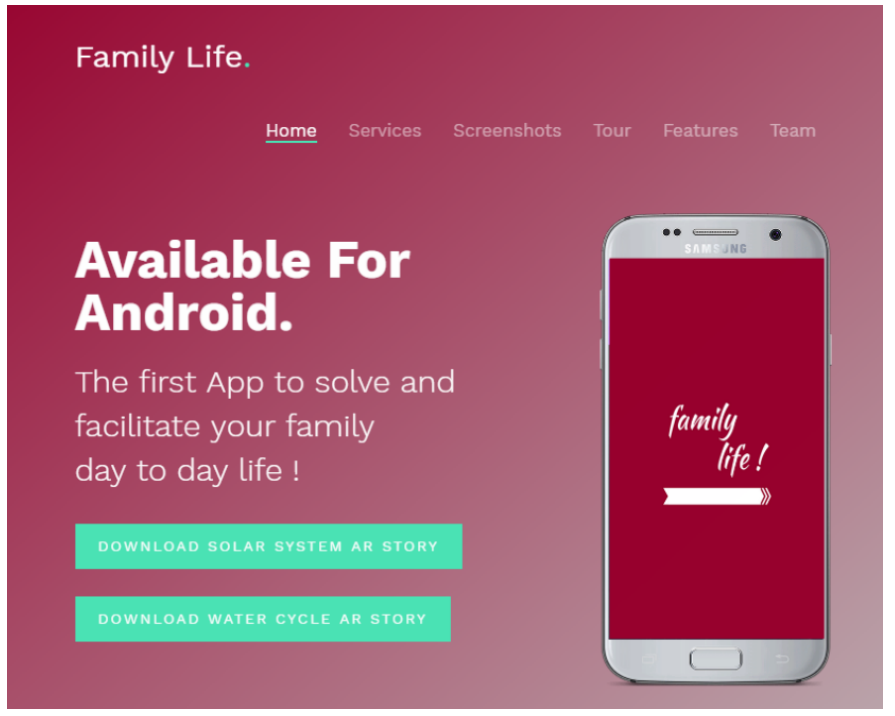

Fig. 6. The website of the FMA mobile application.

reliability, simplicity and popularity. Vuforia has been used to support the Augmented Reality (AR) on mobile applications. Fig. 6 shows the website of the mobile application which consists of six parts (Home, Services, Screenshots, Tours, Features and Team). The screenshots in Fig. 7 illustrates the initial steps of creating accounts for the entire family members. However, the screenshots in Fig. 8 introduces the main services provided by the FMA app.

\section{Evaluation}

In order to evaluate the FMA mobile app, a simple survey was designed and used. The survey was set to assess the user satisfaction about the provided services of the FMA app taking into consideration each service individually. The obtained results are presented below. In Addition, the evaluation was conducted by selecting 24 families randomly. The total number of members of the selected families was 120 individuals (at a rate of five persons per family approximately). Families were asked to download the application and use it for three months (from February $1^{\text {st }} 2019$ to April $30^{\text {th }} 2019$ ) then they had been asked to fill the surveys and the results were reported. The survey was designed carefully to consider the families' satisfaction about each service provided by the FMA app. The survey included nine questions reflecting nine essential factors (facts) about the FMA app and the provided services that are listed as follows:

1) The first question concerned about the Simplicity of the FMA app.

2) The second question interested in the Ease of use of the FMA app.

3) The third question interested to show if the app was a Helpful app in terms of deciding the preferred meal of the day and distributing the chores among the family members.

4) The fourth question interested to show if the FMA app improved the communication skills of the family members during the entire day. 


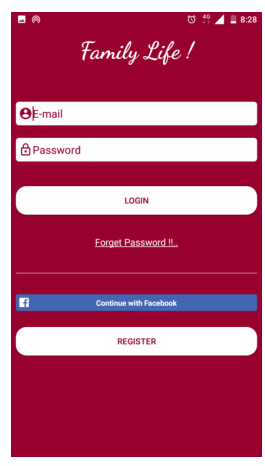

(a)

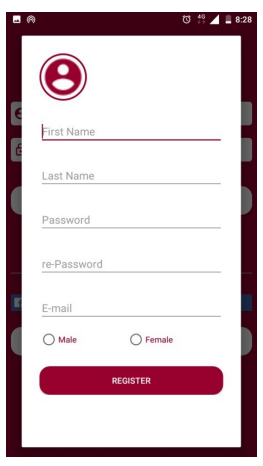

(b)

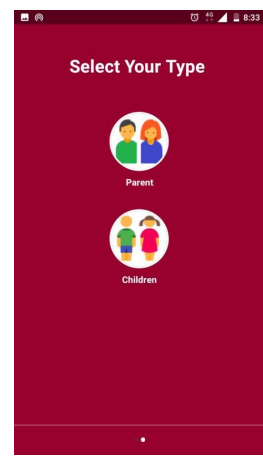

(c)

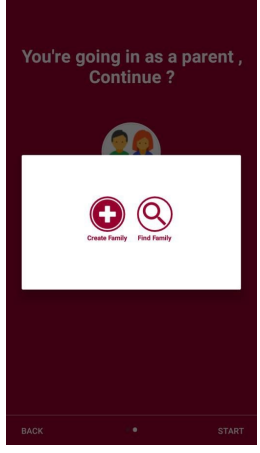

(d)

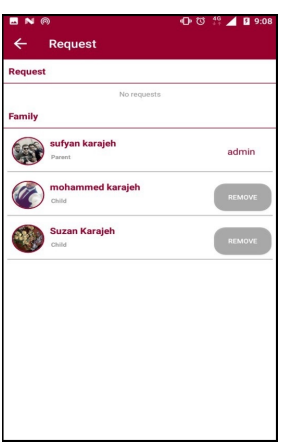

(e)

Fig. 7. A sample of selected screenshots of the FMA app to create family account. (a) Application log-in page, user can choose to log-in or register from this page, registration can be done manually or through using Facebook account. (b) Application sign up page where the user needed to fill the required information. (c) The type of user must be determined to complete the registration process successfully. (d) Users then choose to create a new family count (if user is a parent) or join an existing one. (e) Children request to join the family account.

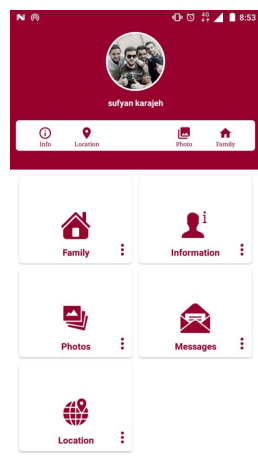

(a)

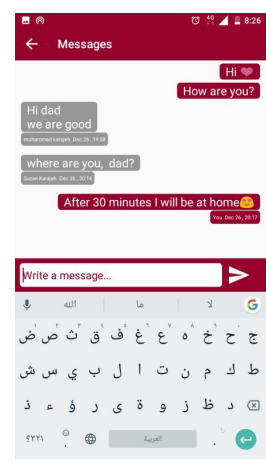

(b)

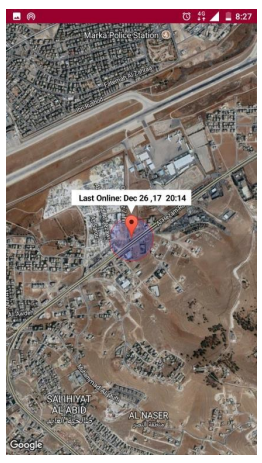

(c)

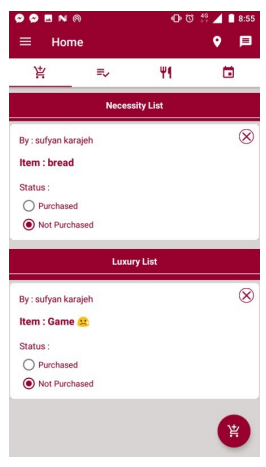

(d)

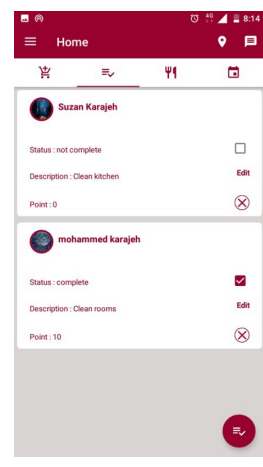

(e)

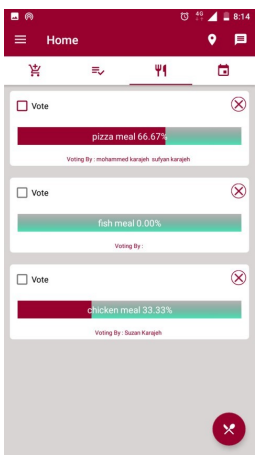

(f)

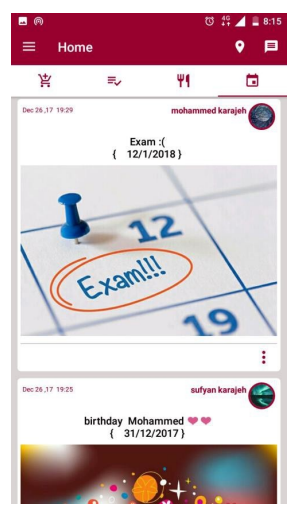

(g)

Fig. 8. A sample of selected screenshots for the main services of the FMA application. (a) The main page. (b) Chat service. (c) GPS locator presents the last seen place of family members. (d) The wish list: the ordinary shopping list and the luxury list. (e) The chores distributed among the children along with the status (completed or not). (f) The meal of the day service. (g) The dynamic calendar with some of upcoming significant events (i.e. exams and birthday's events) added by family members. 
5) The fifth question interested to show an indication about the FMA app time efficiency.

6) The sixth question interested to show if the FMA app was an informative app as it provides information about (but not limited): (i) the daily shopping list, (ii) important events such as exams and school parent meetings and so on and (iii) current position of family members.

7) The seventh question interested to show if the FMA app was capable to follow-up completed tasks that have been distributed to children.

8) The eighth question interested to show if the FMA app improved the educational skills of the children with respect to the provided AR stories.

9) The ninth question asked the users if they would recommend the FMA app to others.

For simplicity, five-scale point of answers was adopted: strongly agree, agree, neutral, disagree and strongly disagree. The results of the questionnaire were reported in Table I. However, the key observations of the obtained results are listed below:

- $\quad$ The average number of participants who agreed on all factors is $86.5 \%$ (agree and strongly agree). Therefore, the majority of users are satisfied with the usability of the proposed FSM app.

- The simplicity is the key feature of the FMA application with a percentage of $96 \%$ on the satisfaction factor. (as shown in Fig. 9a)

- The results indicated that the FMA application could be seen as an informative application with an average of 97\%. (as shown in Fig. 9f)

- A percentage of $98 \%$ of participants agreed to recommend this application to other families and friends as shown in Fig. 9i.

- The results also indicated that the FMA is a helpful app with a percentage of $94 \%$ followed by the factor of ease of use with a percentage of $93 \%$. (as shown in Fig. 9c and Fig. 9b respectively)

- The task follow-up factor achieved a percentage of $83 \%$. However, an extensive future work is still required to improve this feature where the assigned chore for the children should be reported using a percentage value of the accomplished assigned job (fully or partially completion). (as shown in Fig. 9g)

- The percentage of the satisfaction factor of the provided AR stories achieved only 39\% (as shown in Fig. 9h), this is probably due to the limited number of stories (two stories only) and the limited functionality associated with this feature. Therefore, more efforts and elaboration are needed to improve AR service in the future.

However, the reported results show very encouraging results for an early-stage of the FMA app. Further results for each single factor of the survey are presented in Fig. 9 (from Fig. 9a to Fig. 9i).
TABLE I. THE OBTAINED RESULTS OF THE DIFFERENT FACTORS OF THE EVALUATION OF FMA APP

\begin{tabular}{|c||c|c|c|c|c|}
\hline Factors & $\begin{array}{c}\text { Strongly } \\
\text { Agree }\end{array}$ & Agree & Neutral & disagree & $\begin{array}{c}\text { Strongly } \\
\text { disagree }\end{array}$ \\
\hline Simplicity & 113 & 2 & 3 & 2 & 0 \\
\hline Ease of use & 110 & 1 & 6 & 3 & 0 \\
\hline Helpful & 108 & 5 & 2 & 5 & 0 \\
\hline Communication skills & 102 & 5 & 5 & 3 & 5 \\
\hline Time efficiency & 105 & 4 & 10 & 1 & 0 \\
\hline Informative app & 114 & 2 & 3 & 1 & 0 \\
\hline Follow-up & 94 & 5 & 12 & 7 & 2 \\
\hline Educational skills & 34 & 13 & 33 & 23 & 17 \\
\hline Recommendation to others & 113 & 4 & 1 & 2 & 0 \\
\hline \hline Average & $\mathbf{9 9 . 2}$ & $\mathbf{4 . 6}$ & $\mathbf{8 . 3}$ & $\mathbf{5 . 2}$ & $\mathbf{2 . 7}$ \\
\hline Percentage & $\mathbf{8 2 . 7 \%}$ & $\mathbf{3 . 8 \%}$ & $\mathbf{6 . 9 \%}$ & $\mathbf{4 . 4 \%}$ & $\mathbf{2 . 2 \%}$ \\
\hline
\end{tabular}

\section{CONCLUSION AND FUtURE WORK}

This paper presents a comprehensive mobile application that intends to facilitate families' daily life in terms of improving the communication and collaboration between the family members. The Family mobile application can be seen as a very helpful, useful and beneficial app for families to manage their everyday challenges. The proposed FMA application has been developed using two platforms; a website and mobile technology. The proposed FMA app provides a set of services such as suggest the meal of the day, vote on the preferred meal, remind members with important events, track the position of the family members and assign household task to children. The parental responsibilities are carefully adopted and imitated while designing and implementing the different services such as (but not limited): (i) accepting the member request to join the family, (ii) suggesting the meal of the day to be voted by the children (iii) assigning tasks (chores) to children and (iv) checking the completion status of the assigned task. In addition, tracking the position of the family members is one the important services provided by the FMA app. The evaluation of the application was conducted to assess the satisfaction of families. The reported results show very promising results where $86.5 \%$ of users were happy, satisfied and very pleased with the provided services of the FMA application. However, for additional future work, a set of suggestions to improve the provided services are listed in the following points: (i) the enhancement of the AR services to cover a wide range of stories, (ii)using machine learning techniques to compare the assigned chore accomplished by the children with a standard previously stored task so that the completed task can be described in terms of percentage value (percentage of completion), and finally (iii)Supporting parents to understand and explore the feelings of children such as sadness, anger, fear, stress and depression (an emotional orientation of the application).

\section{ACKNOWLEDGMENT}

The authors would like to thank the Hashemite University for their continuous help and endless support, and acknowledge the implementation inputs of Yazeed Asaad, Ahmed Assaf and Sufyan Karajeh in this research. 


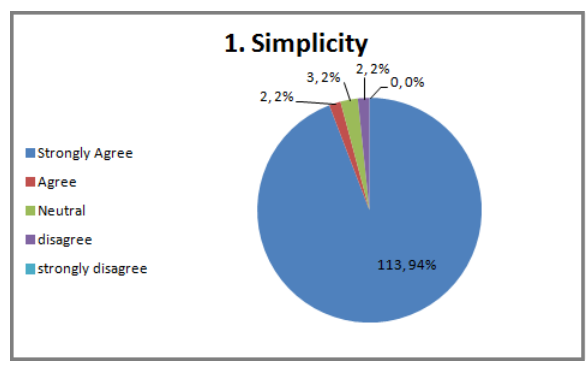

(a) The obtained results of Simplicity factor

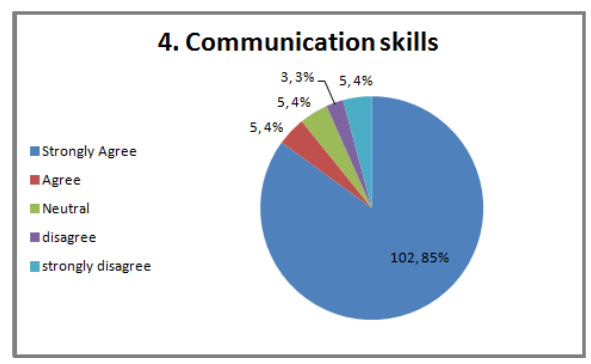

(d) The obtained results of "communication skills" factor

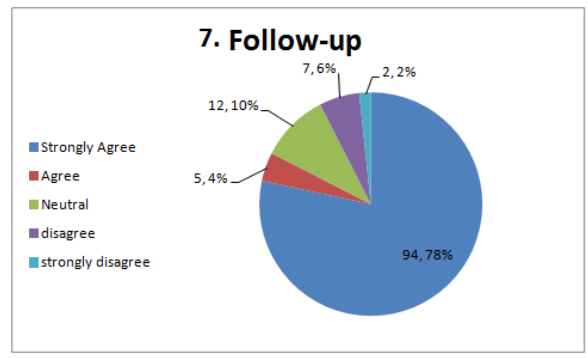

(g) The obtained results of the "Follow-up" factor

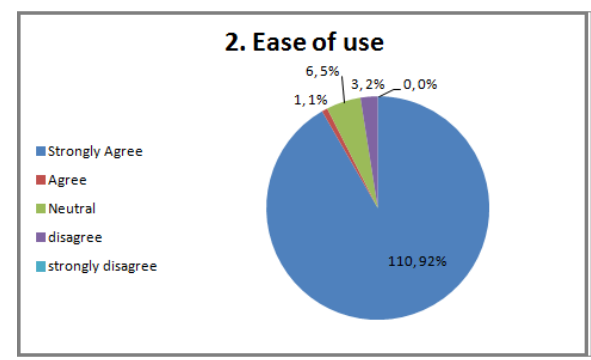

(b) The obtained results of Ease of use factor

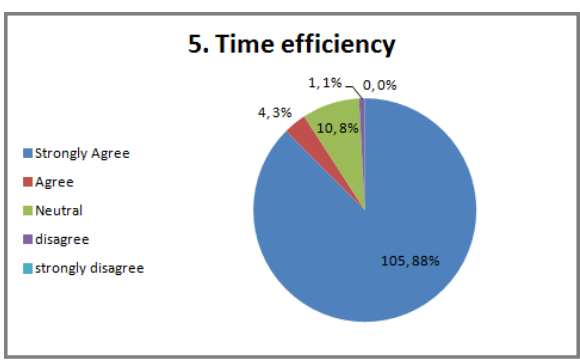

(e) The obtained results of "Time efficiency" factor

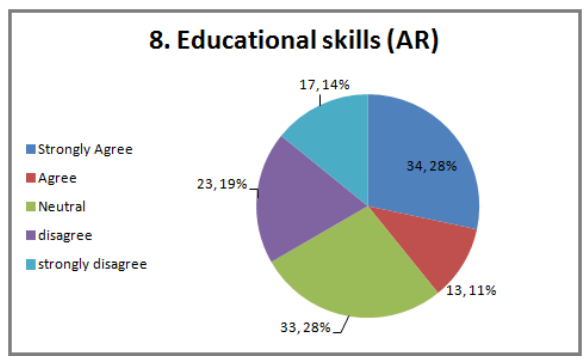

(h) The obtained results of "Educational skills" factor

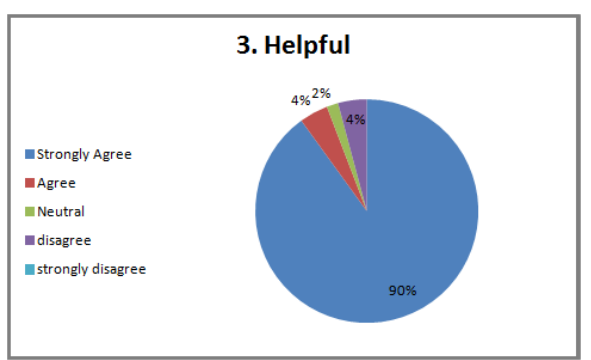

(c) The obtained results of "helpful" factor

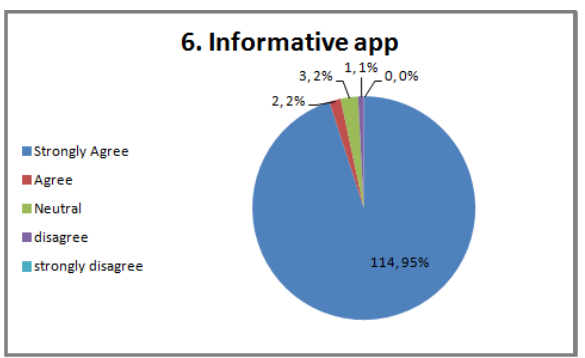

(f) The obtained results of "Informative" factor

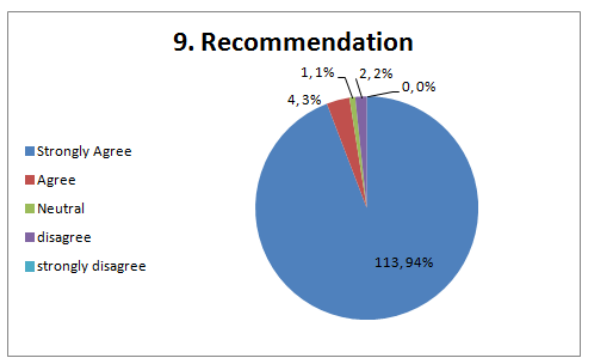

(i) The obtained results of "recommendation" factor

Fig. 9. The obtained results of the distributed survey regarding different factors: (a) Simplicity factor, (b) Ease of use factor, (c) Helpful factor, (d)

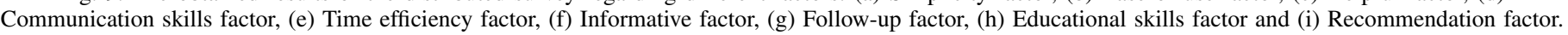

\section{REFERENCES}

[1] M. R. Sanders, K. Burke, R. J. Prinz, and A. Morawska, "Achieving population-level change through a system-contextual approach to supporting competent parenting," Clinical child and family psychology review, vol. 20, no. 1, pp. 36-44, 2017.

[2] C. Doukas, T. Pliakas, and I. Maglogiannis, "Mobile healthcare information management utilizing cloud computing and android os," in 2010 Annual International Conference of the IEEE Engineering in Medicine and Biology. IEEE, 2010, pp. 1037-1040.

[3] T. Page, "Application-based mobile devices in design education," 2014

[4] M. Eberl, "An application of pls in multi-group analysis: The need for differentiated corporate-level marketing in the mobile communications industry," in Handbook of partial least squares. S Springer, 2010, pp. 487-514.

[5] R. N. Akram and R. K. Ko, "End-to-end secure and privacy preserving mobile chat application," in IFIP International Workshop on Information Security Theory and Practice. Springer, 2014, pp. 124-139.

[6] L. Leung, "Effects of ict connectedness, permeability, flexibility, and negative spillovers on burnout and job and family satisfaction," Human Technology: An Interdisciplinary Journal on Humans in ICT Environments, 2011.

[7] K. Romero-Ruiz, L. Echeverri-Sánchez, J. Peña-Plata, S. VásquezGiraldo, M. Aguilera-Cardona, C. Herazo-Avendaño, A. Valencia-Arias, and L. Bran-Piedrahita, "Information and communication technologies impact on family relationship," Procedia-Social and Behavioral Sciences, vol. 237, pp. 30-37, 2017.

[8] L. Kerawalla and C. Crook, "Children's computer use at home and at school: context and continuity," British Educational Research Journal, vol. 28, no. 6, pp. 751-771, 2002.

[9] L. Blackwell, E. Gardiner, and S. Schoenebeck, "Managing expectations: Technology tensions among parents and teens," in Proceedings of the 19th ACM Conference on Computer-Supported Cooperative Work \& Social Computing. ACM, 2016, pp. 1390-1401.

[10] M. d. C. Aguilar Ramos and J. J. Leiva Olivencia, "La participación de las familias en las escuelas tic: análisis y reflexiones educativas," Pixel-Bit. Revista de Medios y Educación, 40, 7-19., 2012.

[11] R. Kraut, T. Mukhopadhyay, J. Szczypula, S. Kiesler, and B. Scherlis, "Information and communication: Alternative uses of the internet in households," Information Systems Research, vol. 10, no. 4, pp. 287303, 1999.

[12] A. M. Moore, “A parent's look at technology," Montessori Life, vol. 18, no. 2, p. 11, 2006.

[13] A. Franzen, "Does the internet make us lonely?" European Sociological Review, vol. 16, no. 4, pp. 427-438, 2000.

[14] J. Goodman-Deane, A. Mieczakowski, D. Johnson, T. Goldhaber, and P. J. Clarkson, "The impact of communication technologies on life and relationship satisfaction," Computers in Human Behavior, vol. 57, pp. 219-229, 2016. 
[15] M. Lasen, "Education and career pathways in information communication technology: What are schoolgirls saying?" Computers \& Education, vol. 54, no. 4, pp. 1117-1126, 2010.

[16] S. Huisman, A. Edwards, and S. Catapano, "The impact of technology on families." International Journal of Education \& Psychology in the Community, vol. 2, no. 1, 2012.

[17] C. Neustaedter, A. Brush, and S. Greenberg, "A digital family calendar in the home: lessons from field trials of linc," in Proceedings of Graphics interface 2007. ACM, 2007, pp. 199-20.

[18] S. Razavi Emadi, "Family time management platform," 2018.

[19] S. Khan, W. Ahmad, R. Ali, and S. Saleem, "A research on mobile applications for location tracking through web server and short messages services (sms)," VFAST Transactions on Software Engineering, vol. 7, no. 2, pp. 12-17, 2015.

[20] A. Al-Mazloum, E. Omer, and M. Abdullah, "Gps and sms-based child tracking system using smart phone," Int. J. Electr. Comput. Electron. Commun. Eng, vol. 7, no. 2, pp. 171-174, 2013.

[21] S. Z. Sweidan, R. Saifan, K. A. Darabkh, S. Abu-Kaff, and S. Al-Ali, "Kids' tracker: An android application for tracking children," Journal of Software Engineering and Applications, vol. 10, no. 13, p. 907, 2017.

[22] A. Cockburn, "Structuring use cases with goals," Journal of ObjectOriented Programming, vol. 10, no. 5, pp. 56-62, 1997.

[23] — Writing effective use cases. Addison-Wesley Professional, 2000.

[24] M. Billinghurst, A. Clark, G. Lee et al., "A survey of augmented reality," Foundations and Trends $₫$ in Human-Computer Interaction, vol. 8, no. 2-3, pp. 73-272, 2015.

[25] C. Xiao and Z. Lifeng, "Implementation of mobile augmented reality based on vuforia and rawajali," in 2014 IEEE 5th International Conference on Software Engineering and Service Science. IEEE, 2014, pp. 912-915. 